\title{
Variation in the fees of medical specialists: problems, causes, solutions
}

\author{
Ian S McRae', Kees C van Gool ${ }^{2}$
}

\section{Greater transparency in setting charges may be the} most efficient way to rein in excessive fees
A rticles in this issue of the $M J A^{1,2}$ and elsewhere ${ }^{3-5}$ have reported significant variation in the fees charged by specialist physicians and surgeons. These variations raise questions about excessive health care costs, as well as about barriers to access for patients. ${ }^{2,4,5}$

That costs are barriers to medical care in Australia has been reported by $8 \%$ of people who needed to see a medical specialist and by $19 \%$ of those needing to see a general practitioner. ${ }^{5}$ International studies have also found that cost is a barrier for those needing medical specialist or general practice care; Australian prices generally fall in the middle range of the countries surveyed, but are among the highest for patients with certain chronic conditions. ${ }^{6}$ Financial barriers are more significant for poorer, sicker people, and for those in remote areas, ${ }^{7}$ and in the long run may lead to poorer health and greater costs.

The causes of fee variations are essentially market-related. Supply and demand conditions vary across geographic and specialty markets, and areas with fewer doctors are likely to face higher fees.? Price variations are also a symptom of the uncompetitive nature of markets for certain medical specialist services, so that some doctors are able to charge well above the levels commonly charged for these services. Whether supply is adequate depends on demand, and this in turn depends on the patients' clinical needs, their ability and willingness to pay (both strongly linked to income), ${ }^{3}$ and their ability to find alternative care (in public hospitals, for instance). Supply the services that will be provided at a given price - depends on doctor numbers, the hours they are prepared to work, and on their attitudes to charging, including views on altruism.

The future supply of medical specialists will be influenced by the growing number of graduates from medical schools, subject to specialist training capacities. ${ }^{8}$ Increasing medical specialist numbers would be expected to lead to increased bulk-billing and lower average fees, but may also increase the volume of services. Other consequences may be difficult to predict, including changes to employment arrangements, such as greater willingness to become salaried medical officers.

Some of the proposed solutions for reducing excessive fees and high co-payments are unlikely to have a substantial impact. For example, there are calls to remove the Medical Benefits Schedule (MBS) fee freeze. ${ }^{2}$ However, evidence from general practice ${ }^{9}$ and the MBS safety net ${ }^{10}$ suggest that increasing the levels of rebates would have minimal impact on out-of-pocket costs, as doctors are aware of what price "the market will bear". ${ }^{1}$ More importantly, such changes are unlikely to reduce variations within medical specialties, or to reduce the extreme out-of-pocket fees charged by some practitioners.

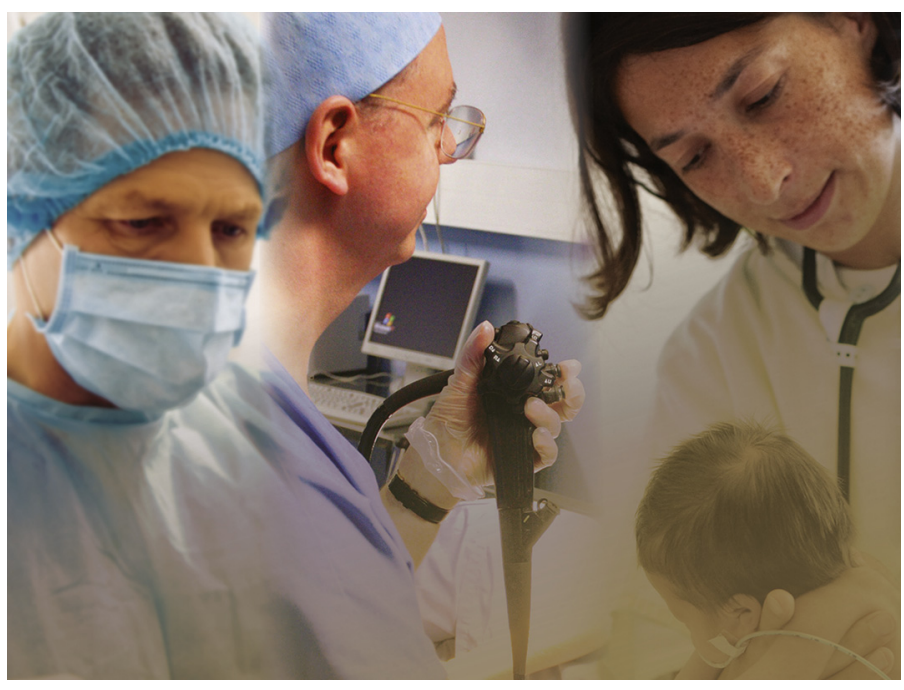

Other self-regulatory solutions, such as professional colleges offering education about "reasonable" fee-setting (eg, the Royal Australasian College of Surgeons Code of Conduct ${ }^{11}$ ) have, in practice, not constrained fees. Colleges may find this role easier were government price setting more transparent and rules for setting MBS schedule fees more explicit.

Easier access to information may induce greater competition. Patients have little opportunity to verify claims of higher quality care by medical specialists, and it is difficult to shop around to find the best price. Unverified quality claims can lead to extensive price variation, despite there being little evidence that quality is correlated with price. $^{2}$ Information for patients could be improved by a website where medical specialists report their fees (eg, myDr. com.au, healthdirect.gov.au), enabling patients and referring GPs to make clinically and financially informed choices. Equally importantly, transparent pricing could lead to price competition between medical specialists.

Extreme out-of-pocket costs could also be reduced by regulatory incentives and constraints within the Medicare system. Noting the constitutional need to avoid civil conscription, options could include removal of access to Medicare rebates for a service if the fee is extreme; introducing incentives, similar to GP bulk-billing incentives, that reward medical specialists for charging certain patient populations specified fees; or through more radical measures, such as making Medicare an opt-in system for doctors who agree to meet particular charging guidelines.

Variations in fees charged by particular medical and surgical specialist groups can generate barriers for patients. History suggests self-regulation is unlikely to change this situation, and increasing MBS rebates will have little effect. While the increasing numbers of specialists should put downward pressure on prices, 
the scale of this pressure is difficult to predict. If the government wants to improve the affordability of medical specialist services without incurring large, uncontrollable costs, direct regulation is one option, but one that is likely to generate considerable debate. Improving the transparency of pricing could increase competition and place downward pressure on unreasonable fee-setting, and may provide the most affordable and fair approach to the problem.

Competing interests: No relevant disclosures.

Provenance: Commissioned; externally peer reviewed.

(c) 2017 AMPCo Pty Ltd. Produced with Elsevier B.V. All rights reserved.

1 Freed GL, Allen AR. Variation in outpatient consultant physician fees in Australia by specialty and state and territory. Med J Aust 2017; 206: 176-180.

2 Hillis DJ, Watters DAK, Malisano L, et al. Variation in the costs of surgery: seeking value. Med J Aust 2017; 206: 153-154.

3 Johar M, Mu C, Van Gool K, Wong CY. Bleeding hearts, profiteers, or both: specialist physician fees in an unregulated market. Health Econ 2016; doi: 10.1002/hec.3317.
4 Callander EJ, Corscadden L, Levesque JF. Out-of-pocket healthcare expenditure and chronic disease: do Australians forgo care because of the cost? Aust J Prim Health 2016; doi: 10.1071/PY16005.

5 Australian Bureau of Statistics. 4839.0. Patient experiences in Australia: summary of findings, 2014-15. Nov 2015. http://www.abs.gov.au/AUSSTATS/abs@.nsf/ DetailsPage/4839.02014-15?OpenDocument (accessed Dec 2016).

6 Schoen C, Osborn R, Squires D, Doty MM. Access, affordability, and insurance complexity are often worse in the United States compared to ten other countries. Health Aff (Millwood) 2013; 32: 2205-2215.

7 Duckett S, Breardon P, Farmer J. Out of pocket costs: hitting the most vulnerable hardest. Melbourne: Grattan Institute, 2014. http://grattan.edu.au/wp-content/uploads/2014/07/ Grattan_Institute_submission_-_inquiry_on_out-of-pocket_costs___FINAL.pdf (accessed Dec 2016)

8 Joyce CM. The medical workforce in 2025: what's in the numbers? Med J Aust 2013; 199 (5 Suppl): S6-S9. https://www.mja.com.au/journal/2013/199/5/medical-workforce2025-what-s-numbers

9 McRae I, Butler JR. Supply and demand in physician markets: a panel data analysis of GP services in Australia. Int J Health Care Finance Econ 2014; 14: 269-287.

10 Van Gool K, Savage EJ, Viney RC, et al. Who's getting caught? An analysis of the Australian Medicare Safety Net. Aust Econ Rev 2009; 42: 143-154.

11 Royal Australasian College of Surgeons. Code of conduct. 2016. https://www.surgeons.org/ media/24335322/2016-04-29 mnl racs code of conduct.pdf (accessed Dec 2016). 